\title{
E-Government Development \& Digital Economy: Relationship
}

\author{
Mohammad Gias Uddin \\ $\mathrm{PhD}$ Student \\ Department of Economics and Business \\ University Tunku Abdul Rahman, Malaysia \\ mail: mdgias89@gmail.com \\ Mohin Uddin \\ Lecturer \\ Department of Business Administration \\ International Islamic University Chittagong, Bangladesh \\ E-mail: mohinIuddin2@yahoo.com
}

\begin{abstract}
The main objective of this examine is to explore the elements that influencing the digital economic system and E-government courting. Commonly, the examiner is to analyze the impact of demographic variables are gender and schooling stage; as well as digital infrastructure, virtual readiness, virtual content material, and offerings on the digital economy in Malaysia. A minimum overall of 384 questionnaires could be disbursed to the goal respondents to collect the sample information. Four hypotheses helping to the developed to survey the particular targets of the examiner. Demographic variables expected to have a high-quality enormous relationship with the virtual financial system. Last however now not least, the findings of the look at shall offer statistics to E-government to understand what factors will affect the virtual economic system. Except, it shall additionally provide useful information for E-government to higher fit their people's needs. The elements decided to boom high-quality dating among Egovernment and virtual financial system in Malaysia.
\end{abstract}

Keywords: Digital Economy, E-Government, Digital Infrastructure, Digital Readiness, Digital Content, and Services.

\section{Introduction}

World over past years economic going to traditional base (e.g: Industrial, agriculture) but recent few years world move to digital economy which base on digital technology (EIU) Economist intelligence unit 20I0, Agnew I999 \& Tapscott I999. So recently everywhere in the world technology development and people involved with social media (communication with social media), ebusiness, the transformation has changed to e-government (Government offering E-government service for the citizen; Karen Mossberger et al 2008; Weill \& Woerner, 2013). Digital economic its helps to economic growth research paper shows that (Brynjolfsson \& McAfee, 20II).

Alongside the advancement of digitalization, an amazing majority of governments have applied e-authorities tasks, even though the volume and scale in their implementation very substantially amongst nations (United international locations, 2012; Nograšek and Vintar, 2014). The sector financial institution (2008) defines e-authorities as using facts technology to improve business tactics and carrier delivery through authorities' departments and different authorities entities.

Dunleavy et al. (2006, p. 467) describe this fashion as "virtual-generation governance", that is perceived with the aid of many researchers as critical for the emergence of post-New Public control governance (e.g. Cordella and Iannacci, 20I0; Margetts and Dunleavy, 2013). The e-government fashion "Offers a possibly unique opportunity to create self-maintaining change, in a vast variety of intently connected technological, organizational, cultural, and social consequences” (Dunleavy et al., 2006, p. 467). In this regard, the character and the consequences of e-government come to be multidimensional and complex.

But, to date empirical research supported through sound and hooked up theories to recognize the technique and the transformative effects of digitalization on public management is sparse (Bekkers and Homburg, 2007; Andersen et al., 2010). The literature review of Heeks and Bailur (2007) and Yildiz (2007) find that most of the e-authorities' fashions within the literature have no strong theoretical grounding. Also, Shareef et al. (201I) locate that modern research tends to deal with special views on this complicated phenomenon in a scattered fashion. 


\section{I.I Background of Study}

This look at seeks to cope with those weaknesses in the existing literature in three methods. First, it applies a multidimensional method to apprehend and seize the multifaceted courting among e-government development and the digital economic system. In this regard, it elaborates on the idea via Zhao et al. (20I4a) that contextual factors including existing social, political, monetary, demographic, IT, cultural factors have interaction and play a great function inside the international procedure of e-authorities adoption and virtual development. Second, the examination is grounded on sound and well-set-up theories, appreciably the generation popularity version (TAM) (Davis, I989) and the generation enactment framework of Fountain (200I, 2005). The former makes a specialty of expertise user adoption behavior while the latter tries to capture the effect of contextual technological, social, institutional, and political elements on generation adoption. In doing so, this examine contributes to more accurate and comprehensive know-how of the relationship between the two. Third, this look is empirical, engaging in a global look at of sixtyseven countries using authentic international records units which include the UN's e-authorities survey and the Economist Intelligence Unit's (EIU) digital economy rankings. For this reason, the results of the study will have wider applications for policymakers on the national stage.

Therefore, it causes studies gaps for this study inside the following:

Research Gap I: Lack of the systematical study of the conceptual framework

Research Gap 2: Lack of the empirical study of the factors e-government development and digital economy

Hence, the goal of this research is to evaluate and validate the determinants of e-authorities improvement and digital financial system.

\section{I.I.I Definitions of E-government}

E-government is using statistics and communique technologies (ICTs) to enhance the sports of public quarter organization. some definitions restrict e-government to internet-enabled programs best, or simplest to interactions among authorities and outside agencies.

\section{I.I.2 What is the digital economy}

The digital economy refers to a financial system that is based totally on virtual computing technology. The virtual economy is likewise once in a while referred to as the net economic system, the brand-new economy, or the internet financial system. An increasing number of, the "virtual economy" is intertwined with the conventional economic system creating a clean delineation harder.

\section{I.2 Problem Statement}

The relationship between e-power systems and virtual finance. As expected, there may be a very strong correlation between the composite index for electronic authority development and the overall score for the virtual economy. To further test the relationship between the 2, we run SEM. The advantage of using SEM is that it takes account size into account to determine the relationship between a higher e-authority and the virtual economy. The SPSS software is used to generate estimates of maximum probability parameters. The healthy index is based entirely on strong changes in focus. The effect is to confirm that there may be a strong correlation between e-government and the digital economy. All the indices show a valid and healthy information model. Based on the results of each evaluation, we can confidently conclude that e-government contributes to and undermines the development of the virtual economy.

\section{I.3 Research Question}

- What are the elements that impact dating between e-government service development and the digital economy system?

\section{I.4 Research Objective}

- To determine the elements impact relationship among e-government service development and the digital economy system

\section{I.5 Significance of the Study}

Current years have witnessed speedy developments in e-government further to e-employer inside countries across the world. Although each e-authorities and e-industrial organization contribute in the direction of national monetary usual overall performance.

These research findings will demonstrate the huge and intertwined roles of e-authorities and e-industrial enterprise in improving the countrywide financial performance. A good way to enhancing countrywide monetary income, this research indicates that policymakers must recall measures to beautify the development of e-government and e-company collectively. 


\section{I.6 Organization of Study}

The next part of this thesis discusses the basic concepts of this research theory, which helps to formulate your hypotheses and the research framework. The next section explains the methodology and presents the statistical results, while the next section discusses the results and their implications for the development of policies and theories. Therefore, the limitations of the research and the suggestions for future research are analyzed before considering the main contributions of the study

\section{Literature Review}

\section{I Introduction}

According to an Economist Intelligence Unit (EIU) ()2010, Agnew 1999, and Tapscott 1999, in the world economy was used by the traditional basis in the past years like industrial organization, agriculture, Farming, and so on. But now, these traditional economy turns into the digital economy by the use of digital technology and providing ICT benefits of the customer, government, and businesses of a country. Allowing by the government of many countries, the digital economy helps to support the people and society of the countries. Digital economy helps to digitalize the trade, market, and economics through technology.

\subsection{Definition of Digital Economy}

The definition of Brynjolfsson and McAfee, 20II, shows that the digital economy plays a role to increase the economic growth of a country. By the digital economy, the government can establish e-government which increases the market value of products and services and helps to measure the Gross Domestic Product or GDP of a country. Also helps to measure Gross National Product or GNP to increase foreign earning by the technology.

Tapscott (1996), describes the digital economy as the new framework which is created with the help of human and their intelligence. There are some characters associated with the digital economy that our knowledge of people, digitalization on activities, internetworking with the activities, innovative assets, and so on. All of these characters help the world to make more digital than the traditional industrial economy. He also added that the contemporary position regarding connectedness with the various concepts is created with the help of the digital economy.

From OECD broadband statistics, the digital economy is the more digital and established network. It is using in various workplace to reduce problems, increasing skills and opportunities for individuals and groups, and make them successful in different fields. According to OECD, about 22 of percent people are related to ICT activities for establishing themself. Digital economy increases opportunities and options for individuals, consumers, workers, the government of one country.

\subsection{Definition of E-Government}

Dunleavy et al. (2006), he establishes a new digital era government (DEG) defines that this DEG is used for the societal, economic, technological development in many countries. By DEG a government can provide better services, quick delivery of products to the clients, create digitalization for the public services. For using the digital era government, they can use cloud computing, social web, and so many apps. Some Researchers from different countries use to post contemporary civil administration government.

\subsection{Definition of Digital infrastructure}

By Davis 1989, well-established theories were made, most significantly use the Technology Acceptance Model (TAM). According to Davis, he includes how these models accept by the people and use to establish the activities of users. Many factors used by them how to use when to use the model to make and involve the economic government. Perceive use fullness and perceive comfort about consume is the main task and circumstances toward use model. He focuses on the formal acceptance of the model and creates an impact on the social, economic, political, institutional factors to adopt a model. This model creates an accurate and appropriate understanding and a relationship between the digital economy and e-government.

\subsection{Definition of Digital Readiness}

According to Fountain 200I, p I0, Technology is increasing more than in past years. Technological objectives like hardware, software, network capacity is upgrading their storage day by day. It helps to create more digitalization in the world. These digital activities involved with multiple roles that make interaction and create influence between digitalization and technology.

\section{Hypothesis Development}

The TAM method framework by Davis I989, defines that both the digitalization and e-government with the technology involved with economics, sociology, politics, management, culture, and so on. He included that the TAM method and variable approaches show the hypothetical relationship between the e-government and digital economy.

Economist Intelligence Unit (EIU) 2010 measures an economy on the digital economy. It rests with the culture of an economy that effects the digital economy. 


\section{I E-Government}

Dunleavy et al., 2006, p. 467, also added that E-Government provides a unique opportunity for a country to make a dramatic change for its people. It provides technical opportunities to their people so that can be technically skillful to do any kind of job. It helps in organizational activities like training the employees for use of a machine, more production, and resource allocation, and so on. It also makes a unique change of culture which makes them different from others and also social effects. All of these factors are relating to each other on e-government. Including all of these factors, the government turns into multi-dimensional and operates all those activities which are more complex than before.

Doong, H., Wang, H., and Foxallc, G.R. (2010) said that a psychological approach is used to examine the classical models, use the existing literature, adaption of citizenship, innovation cognitive styles, and involvement influence the loyalty intentions. Higher loyalty intention is related to the e-government. People involved in the loyalty intention and other sectors to use in e-government. Some psychological factors are associated with e-government and try to help better activities than before.

World bank 2008 defines that e-government is increasing with the use of technology. By information technology government increases its business activities, services provided to the clients and society with the help of the government departments, and other governmental entities.

According to, Bélanger, F. and Carter, L. (2012), the e-government creates a new domain with information technology which shows the interaction between the government constituents. Previously e-government was themed by the information system, political science, public administration, and so on. Along with the information system, e-government can create theoretical activities, methodology, sampling, and so on. Over time e-government discover much new knowledge, relations, era for the people and society of own country.

According to Björn, N., Elena, G., and Ralf, P. (2012), E-government with the help the digital economy makes the mutual benefits for both the citizens and public administration. Through the use of the internet, different kinds of internet adoption help to improve the concept of e-government. There is some corresponding research model social-demographic factors like age, gender helps to make the e-government more perfect. E-government distinguishes the user from an online user and traditional user of technology, institution, social activities and motivate people and train them to increase activities through the digital economy and develop of e governmental activities.

The definition of Bretschneider, S. (2003) shows that informational technology slowly enters into all fields of government like governmental organizations, institution, and so on. This information technology converts all the data of governmental activities analog to digital. It makes the organization of the government and digital evaluation analyzes the activities effectively and efficiently. E-government with the help of the internet collect data from all the parts of the country, delivers services online, also provides direct delivery of services to their clients. Information technology also helps the government to restructure the organization, an institution of government, in the developed countries, the information system uses the most. It uses both the government and political activities, through the digital economy.

Coursey, D. and Norris, D.F. (2008) said so investigation activities within E-government are new. He suggests using some model to test the accurateness of the government. These methods help to identify activities associated with e-government and the actual development of e-government. Locale governmental activities are more informative and accurate to reduce the problem associated with them. But those models cannot accurately describe the development of e-government. They link both the information technology and government to predict and observe the activities associated with the government.

\section{HI: E-government is positively related to the influence of the digital economy}

\subsection{Digital Infrastructure}

Cordella and Iannacci, 2010; Margetts and Dunleavy, 2013 also analysed the digital era environment. They use the system in the post-management government system. After developing the model, the researcher uses it in the rural or insolvent area in the world. By training, the employees make them more skillful. Digital era government makes the organization, institution more successful, and provides services to their clients through the internet. The digital government also called e-government reaches the appropriate level with the help of better technology.

The rapid growth of information technology also increases the help of information and communication technology in a broad sense. ICT help us to reshape our life and business activities globally. The internet with the help of information technology has become a vital infrastructure all over the world. According to the World Economic Forum (20I4), the use of the internet is increasing all over the world of $1.5 \%$ for per capita GDP growth. The digital access with the help of internet infrastructure provides services and help to the individuals, businesses, geographical area, society, and other emerging economic activities. Digital infrastructure also helps to increase the digital economy and e-government with increasing skills.

According to World Bank (2016), Digital infrastructure with the help of technology increases the number of information, reducing the cost rate, reducing difficulties, bringing better innovation, sharing information, and so on. It creates better connectivity among, people, businesses, and government. The ultimate goal of the digital economy is to provide equal

(C) (i) \& Copyright (C) CC-BY-NC 2020, CRIBFB | AESR


facilities in the organization and so on. The new use of ICT and the internet creates a new economy which increases transparency, reducing the inefficiency of a lack of information, and so on.

Bertot, J.C., Jaeger, P.T., and Grimes, J.M. (2010) include that many governments want to change their activities effectively and transparently. Information and communications technology (ICT) are more cost-effective to promote the activities of the government. E-government is increasing providing comprehensive support for the nations. Information technology and ICT both try to make good e-government and transparent activities. ICT provides updated information, transparency to the society, good initiatives to take, building a better culture, changing agent, and so on.

\section{H2: Digital infrastructure is positively related to the influence of the digital economy}

\subsection{Digital Readiness}

Economist Intelligence Unit (EIU) 2010 and United Nations 2012 show that many data for digitalization are collected from the higher networking system, a well-known website, e governmental policies, and strategies that are involved with these. All of these sources are established by digital readiness with the help of technology.

From the research of Pew Research Centre, With the faster growth of Technology, many people or society are unable to reach in the situation, from 1930, when the electricity was developed for the household services, many American rural people were unable to reach in the opportunities. Internet and Smartphone are increasing day by day. But many people in the world, unaware of these features and activities. They also added that digital readiness has several characteristics which are digital skills, need for every people to access, and use the internet. Second, they need trust to use the digitalization and the third one is using digital technology. The digital economy should ensure that they must reduce the digital realness and train the people to come up with the situation.

The trust, use, and skill of digital readiness can be measured. The Pew Research Centre 20I5, the element of the digital readiness can be measured how satisfied the people are, how can they cope up with the digital economy, how can they learn, etc. Digital learning is also called the way of learning. They concluded that with the help of digital readiness can be more experience, people can learn more and will be more digitalize.

\section{H3: Digital readiness is positively related to the influence of the digital economy}

\subsection{Digital Content and Services}

Carlsson, B. (2004) indicates a new economy that shows the new trend of the economy. This new economy includes digitalization, the combination of the internet creates a new era of technology. It develops the relationship between actors and ideas. These new economies are continuous with the internet, multiple actors and ideas, a good level of connectivity with people and create a longterm goal. With the new trend of the economy, it develops in the production unit, agriculture, operating activities, manufacturing more than tradition.

Erumban, A.A., and de Jong defines that, the use of information communication technology is using day by day. The rate of adoption increases as the income level increases. The adoption rate of ICT is slide related to the national culture and international culture. But most of the time they differ from each other. ICT helps to increase power and reduce uncertainty throughout the country. After creating a balanced level, ICT helps to control the entire problem related to education and income.

Cooper, R.B., and Zmud, R.W. (1990) define Material requirements planning: MRP should be identified and examined clearly. Information technology is related to managerial task to reach the goal. With the Material Requirement Planning method, random sampling is also used to calculate the activities associated with the organization. Information technology includes the adoption, political activities, financial activities, and other activities to examine the infusion associated with the organization. Various important materials should be perfectly planned to reduce wastage and reach their goals.

According to Chinn, M.D., and Fairlie, R.W. (2006), in developing countries, computers, and internet use are increasing. Both developed and developing countries use the penetration rate, adoption rate through technology. The role of a comprehensive set is used in demographical, infrastructure; economic activities are used in the global area. Financial development with stock, trade is used for the growth rate with the use of the internet. In the internet penetration telephone sector, various rates are included to work with the technology and analyze the differences between the computer and other technology with the ICT sector.

Department of Broadband, Communications, and the Digital Economy, Australian Government specifies that eightgoal are used to identify the connectivity and the use of digital technology and helps to set up a vision to associate with the global digital economy. Through the use of the digital economy, people from remote area can find educational, health services. They find out new initiatives for the improvement of the digital future. With the digital economy, the government will become digitalized. A correspondence is used to identify and improve performance and acceptance through online. With the digital economy, the government also uses online mailboxes. ICT skills are also helpful for the digital future of the government. ICT includes technology 
and try to help and develop a relationship with both industries of government and educational institution. The digital economy helps individuals, business people, and non-profits organizations and so on. The government also helps to reach the goal and establish digital platform. The document shows that the digital economy helps to run the objective of the future, reflect the rapid growth digital future.

Chang, I.C., Li, Y.C. defines and creates the model of tax filing system which is reasonably accepted by the clients. He includes many factors to create the intention of the clients to use the system. And the system is related to the information system quality which provides quality information to their clients. These tax systems are used most in the governmental organization, institutions. In the governmental activities, the taxpaying system is used the most provided by the government.

\section{H4: Digital content and services are positively related to the influence of the digital economy}

\section{Research methodology \\ 4.I Conceptual Framework}

According to Fountain 200I, Schellong 2007, various important theoretical models create a conceptual framework for the workplace. They define that the model of Fountains technology makes a structured framework for the government. They also literal on the nation's industrialization activities, bureaucracy, the networking organization of the country, and lastly include governance to provide the society.

Fountain $200 \mathrm{I}$ also added that technology, organizations, institutions help to take a better framework for both the digital economy with the government. A digital economy with the use of information technology can create better opportunities for the government. New technology also helps to make an automatic change. It also makes the change in the organization, the process of an institution, and so on. Fountain defines that the digital economy can make a conceptual framework in governmental activities.

\section{Proposed Conceptual Frameworks}

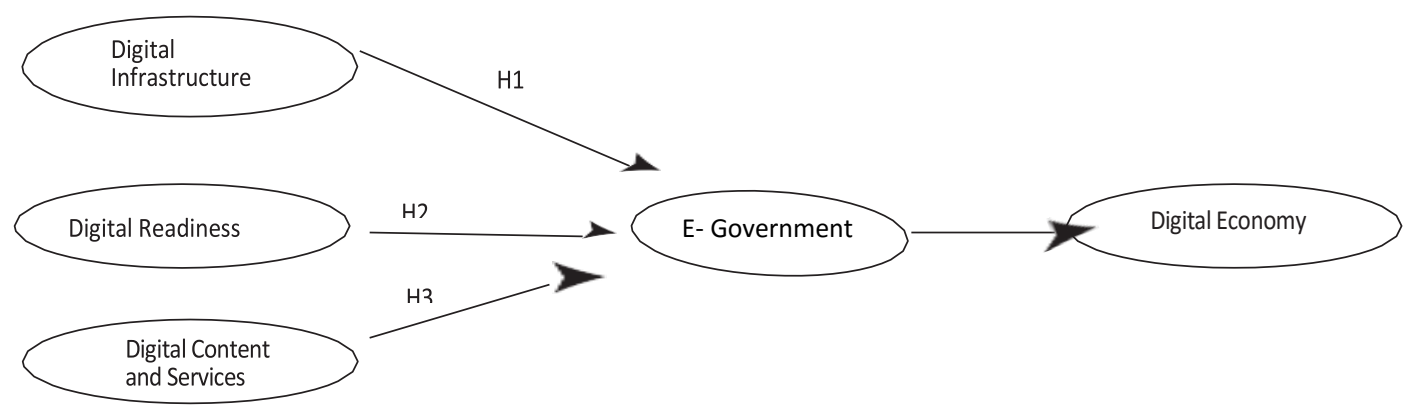

Figure I: Proposed model of the relationship between E-government service development and Digital Economy system

\subsection{Hypothesis}

$\mathrm{HI}$ : E-government is positively related to the influence of the digital economy

H2: Digital infrastructure is positively related to the influence of the digital economy

H3: Digital readiness is positively related to the influence of the digital economy

H4: Digital content and services are positively related to the influence of the digital economy

\subsection{Variables}

4.3.I Independent Variables

-Digital infrastructure

-Digital Readiness

-Digital content and services 


\subsubsection{Dependent Variable}

Digital economy

\subsubsection{Mediating Variable}

E-government

\subsection{Questionnaire Design and Measuring Scale}

Surveys are the easiest and popular way to collect number one statistics. Since this survey is largely based on information number one, the questionnaire form is used as a survey tool. The questionnaire was designed by Google form in an online-based formula. Following, Jezz (2002), the survey way on the global network was convenient, green time, and administrative convenience. This is a good option for connecting populations with greater access and destinations within larger and more diverse populations and special populations that may be a bit difficult to reach "Coomber (1997), Smith and Leigh (I997), Buchanan and Smith (I999)". Furthermore, network online-based questionnaires can give excessive levels of anonymity that increase self-esteem and reduce anxiety and social desirability "Coomber(I997); Joinson(I999)".

We send email to selected respondents for inviting an online-based URL hyperlink where include questioner server shape, the respondents need to completed questionnaire server just 7 to 10 minutes and respondents also get knowledge from the servery

\subsection{Target population and Sampling}

Target population we focus base on Malaysia were people connecting with their e-governance and digital financial system. Totally the population of Malaysia (20I8), thirty million. We use some random sampling for study purpose to know activity with egovernance and digital economic

\subsection{Frequencies Distribution}

One of the methods for displaying specific information is the frequency distribution. So far, a clear and strong information view from respondents. So, this study helps me to get respondents information that can be analyzed using the frequencies distribution function by the SPSS software.

\subsection{Pilot Test}

The submitted questionnaire was examined through experimentation before the last questionnaire was sent to the actual respondents. This test verification is intended are guarantee to the clarity and reliability of the proposed questionnaire and to obtain previously identified complexity. In line with (Malhotra; 2008), it Generally reduced the sample formula with a I5-35 interview.

Table I. Pilot Test Result

\begin{tabular}{ll}
\hline Variables & Cronbach's $\boldsymbol{\alpha}$ \\
\hline Attitudes & 0.854 \\
\hline Subjective Norms & 0.829 \\
\hline Perceived Behavioral Control & 0.653 \\
\hline Self-Identity & 0.786 \\
\hline
\end{tabular}

\subsection{Facts Evaluation}

This view uses four statistical analysis tools: descriptive notes that provide initial information on the demographic background of the respondents, reliability analysis of Alpha Cronbach that examines the reliability of the questionnaire used, analysis of factors related to independent predictive variables of multiple factors and coefficients of correlation Kendall tau_b guarantees correlation coefficients between independent and dependent variables.

\subsection{Descriptive Statistics}

Expositive statistics describe the main skills of statistics. It has given a brief description of the model and presents quantitative measurements or descriptions in a simpler design. In this case, descriptive information is used to evaluate the interviewed demographic inheritance. This demographic context includes gender, age, higher education phase, modern profession, and income phase. 
Which will pump specific and dichotomous records on the SPSS software analysis program for explicate records evaluation? similarly, month-to-month gross earnings are divided into 6 agencies ranging from I to 6 for much less than 2000 RM, 2000 RM to 3999 RM, 4000RM to 5999 RM, 6000 RM to 7999 RM, 8000 RM to 9999 RM, I0000 RM \& above.

\section{IO Reliability Analysis}

The reliability evaluation offers statistics when referring to the relationship between the elements of the character tool.

Table 2.Comparing the Cronbach's Alpha for a different number of variables but the same average correlation

\begin{tabular}{lll}
\hline Average Correlations & No. of Variables & Cronbach's Alpha $(\boldsymbol{\alpha})$ \\
\hline 0.5 & $\mathrm{I}$ & 0.500 \\
\hline 0.5 & 2 & 0.667 \\
\hline 0.5 & 3 & 0.750 \\
\hline 0.5 & 4 & 0.800 \\
\hline 0.5 & 5 & 0.833 \\
\hline 0.5 & 6 & 0.857 \\
\hline 0.5 & 7 & 0.875 \\
\hline 0.5 & 8 & 0.889 \\
\hline 0.5 & 9 & 0.900 \\
\hline 0.5 & I0 & 0.909 \\
\hline 0.5 & II & 0.917 \\
\hline 0.5 & I2 & 0.923 \\
\hline 0.5 & I3 & 0.929 \\
\hline 0.5 & I4 & 0.933 \\
\hline 0.5 & I5 & 0.938 \\
\hline & Source: Nunnally (I978).
\end{tabular}

\section{II Correlations Analysis}

Table 3. Interpretation of the range of Correlations Coefficient analysis

\begin{tabular}{lll}
\hline Positive & Negative & Interpretation \\
\hline+ I.00 & -1.00 & Perfect \\
\hline+0.80 to +0.99 & -0.80 to -0.99 & Very Strong \\
\hline+0.60 to +0.79 & -0.60 to -0.79 & Strong \\
\hline+0.40 to +0.59 & -0.40 to -0.59 & Moderate \\
\hline+0.20 to +0.39 & -0.20 to -0.39 & Weak \\
\hline+0.01 to +0.19 & -0.01 to -0.19 & Very Weak \\
\hline Source: Adopted from Salkind $(2009)$ & & \\
\hline
\end{tabular}

\subsection{Moderated A Couple of Regression}

It is possible to use more than a simple regression or regression model to find the presence of a simple result of the economic situation and the involuntary desire between the digital economy and electronic government. To examine the hypothesis of a direct and moderating relationship between the digital economy and moderate e-government, several regression analyzes were transformed into the following techniques used by "Darrow and Kahl, I982" and "Hair et al, 2010" and "Evans, 1987". The independent variable is in the first phase to obtain an effect of temporal principle in the second degree; Dependent variables are transformed into regressions of independent moderating variables and consist of undistorted variables and moderators.

\subsection{Conclusion}

Finally, you can then perform a Pearson Correlation or Kendall t-test analysis to test the relationship between each of the distorted variables and the variables that are determined based on the results of the normal test. Sooner or later, simplifying more than one 
version of the regression will be used to examine the effects of economic conditions and the relationship between the digital economy and e-government.

\section{Results \& Findings}

The main point of correlation result analysis is to identify the correlation between open digital infrastructure variable, digital availability, digital content and services and, government-dependent variables in the digital economy.

The survey sample study of 430 Malaysians who were randomly selected. Initially, the online questionnaire was designed using Google forms for collecting questioner data. The google form URL send to people via email \& social media platform in November 2018. A total of 320 samples were collected via the online form. Because of the smaller number of respondents in the online google survey form.

Table 4. Population from Respondents

\begin{tabular}{ll}
\hline Questionnaire & Total Number of Responses \\
\hline Google form Questionnaire Distributed & 320 \\
\hline Printed Questionnaire Distributed & I I0 \\
\hline Incomplete Questionnaire & 46 \\
\hline Useable Questionnaire & 384 \\
\hline
\end{tabular}

\section{I Frequency Distribution}

Table 5. Respondents by Demographic Characteristics

\begin{tabular}{|c|c|c|c|}
\hline Variables & By age & Frequency total & Percentage $\%$ \\
\hline \multirow[t]{2}{*}{ Gender } & Male & I9I & 48.6 \\
\hline & Female & 202 & $5 \mathrm{I} .4$ \\
\hline \multirow[t]{5}{*}{ Age } & Below 30 years old & $\mathrm{I} 43$ & 36.4 \\
\hline & 30 to 39 years old & 109 & 27.7 \\
\hline & 40 to 49 years old & 86 & $2 \mathrm{I} .9$ \\
\hline & 50 to 59 years old & $4 \mathrm{I}$ & 10.4 \\
\hline & 60 years old and above & $\mathrm{I} 4$ & 3.6 \\
\hline \multirow[t]{7}{*}{ Highest Education Level } & Total Primary levels & 2 & 0.5 \\
\hline & Total Secondary levels & II8 & 30.0 \\
\hline & Total Diploma levels & 67 & 17.0 \\
\hline & Total Bachelor's degree levels & I69 & 43.0 \\
\hline & Total Master's degree levels & 32 & 8.1 \\
\hline & Total Doctoral degree levels & 4 & 1.0 \\
\hline & Total Others levels & $\mathrm{I}$ & 0.3 \\
\hline
\end{tabular}

\subsection{Reliability Tests}

Table 6. Reliability Test Result

\begin{tabular}{lllll}
\hline \multirow{2}{*}{ Numbers of Variables } & Before & & After \\
\cline { 2 - 5 } & Numbers of Item & Cronbach's $\boldsymbol{\alpha}$ & Numbers of Item & Cronbach's $\boldsymbol{\alpha}$ \\
\hline Digital Infrastructure & 5 & 0.746 & 5 & 0.746 \\
\hline Digital readiness & 5 & 0.655 & 4 & 0.717 \\
\hline Digital contents and service & 6 & 0.672 & 5 & 0.744 \\
\hline E-government & 2 & 0.713 & 2 & 0.713 \\
\hline Digital economy & 4 & 0.457 & 3 & 0.720 \\
\hline
\end{tabular}

Notes: Question 6, II, and I9 from and from to increase Cronbach's $\alpha$ 


\subsection{Factor Analysis}

The factor analysis was performed using the method of extracting the main components on digital economic variables, electronic government, digital infrastructure, digital availability, digital content, and services. As evaluated in Table 4.4, the sample value of the Kaiser-Meyer-Olkin (KMO) measurement factor was 0.817. According to the practical rules proposed by Kaiser (I974), a $\mathrm{KMO}$ greater than 0.8 for this analysis is useful and can be followed by factor analysis. Furthermore, the Chi-square estimated in the Bartlett Sphericity Test was 2090,756 with I7I degrees of freedom and a significant Chi-square value (p <0.00I). Factor analysis is considered a suitable technique for future data analysis.

Table 7. Result of KMO and Bartlett's Test

\begin{tabular}{lll}
\hline $\begin{array}{l}\text { Kaiser-Meyer-Olkin Measure of } \\
\text { Sampling Adequacy }\end{array}$ & 0.817 \\
\hline Bartlett's Test of Sphericity & Approx. Chi-Square & 2090.756 \\
\hline & Df & I7I \\
\hline & Sig. & 0.000 \\
\hline
\end{tabular}

Table 8. Communalities

\begin{tabular}{|c|c|c|}
\hline & Initial & Extraction \\
\hline I) The digital economy has improved the economic condition of Malaysia & I.000 & $.4 \mathrm{II}$ \\
\hline 2) Digital economy supports the sustainable development of Malaysia & I.000 & .596 \\
\hline 3) The digital economy has a positive influence on e-government & 1.000 & .585 \\
\hline 4) Digital economy builds trust towards e-government development & I.000 & .584 \\
\hline 5) The digital economy is helpful for eOgovernment development & 1.000 & .603 \\
\hline 6) E-government has improved the economic condition of Malaysia & I.000 & .383 \\
\hline 7) E-government supports the sustainable development of Malaysia & 1.000 & .537 \\
\hline 8) E-government has a positive influence on the digital economy & 1.000 & .542 \\
\hline 9) E-government builds trust towards digital economy development & 1.000 & .613 \\
\hline I0) E-government is helpful for digital economy development & I.000 & .569 \\
\hline II) Digital infrastructure has improved the economic condition of Malaysia & 1.000 & .503 \\
\hline I2) The digital infrastructure supports the sustainable development of Malaysia & I.000 & .617 \\
\hline I3)Digital infrastructure has a positive influence on the digital economy & I.000 & .565 \\
\hline I4) Digital infrastructure builds trust towards digital economy development & 1.000 & .601 \\
\hline I5) Digital infrastructure is helpful for digital economy development & 1.000 & .731 \\
\hline 16) Digital readiness creates opportunities for the digital economy & 1.000 & .764 \\
\hline I7) Digital readiness support development of the digital economy in Malaysia & 1.000 & .688 \\
\hline I8) Digital readiness has a positive influence on the digital economy & 1.000 & $.66 \mathrm{I}$ \\
\hline I9) Digital readiness builds trust towards digital economy development & I.000 & .555 \\
\hline Extraction Method: Principal Component Analysis. & & \\
\hline
\end{tabular}

Table 9. Digital content \& Services Variable Normality Test of Normality

\begin{tabular}{rrrrrrr}
\hline & \multicolumn{3}{c}{ Kolmogorov-Smirnova $^{\text {a }}$} & & \multicolumn{2}{c}{ Shapiro-Wilk } \\
\hline & Statistic & df & Sig. & Statistic & df & Sig. \\
\hline Digital Content \& Services & .101 & 384 & .000 & .958 & 393 & .000 \\
\hline
\end{tabular}


TableI0. E-government and Chi-Square Test

\begin{tabular}{llll}
\hline Chi-Square Tests & \multicolumn{3}{l}{} \\
\hline & Value & Df & Asymp. Sig. (2-sided) \\
\hline Pearson Chi-Square & $23.554 \mathrm{a}$ & $\mathrm{I} 2$ & .023 \\
\hline Likelihood Ratio & 25.236 & $\mathrm{I} 2$ & .014 \\
\hline $\begin{array}{l}\text { Linear-by-Linear } \\
\text { Association }\end{array}$ & $\mathrm{I} .364$ & $\mathrm{I}$ & .243 \\
\hline $\mathrm{N}$ of Valid Cases & 384 & \\
\hline a. 2 cells (I0.0\%) have expected count less than 5. The minimum expected count is 4.37.
\end{tabular}

Table II. Digital Infrastructure and Chi-Square Test

\begin{tabular}{llll}
\hline Chi-Square Tests & & & \\
\hline & Value & Df & Asymp. Sig. (2-sided) \\
\hline Pearson Chi-Square & 23.554a & I2 & .023 \\
\hline Likelihood Ratio & 25.236 & $\mathrm{I} 2$ & .014 \\
\hline $\begin{array}{l}\text { Linear-by-Linear } \\
\text { Association }\end{array}$ & $\mathrm{I} .364$ & $\mathrm{I}$ & .243 \\
\hline N of Valid Cases & 384 & & \\
\hline
\end{tabular}

Table I2. Digital Readiness and Chi-Square Test

\begin{tabular}{llll}
\hline Chi-Square Tests & & & \\
\hline & Value & Df & Asymp. Sig. (2-sided) \\
\hline Pearson Chi-Square & $\mathbf{3 5 . 7 9 2}^{\mathrm{a}}$ & $\mathrm{I} 6$ & .003 \\
\hline Likelihood Ratio & 34.685 & $\mathrm{I} 6$ & .004 \\
\hline Linear-by-Linear Association & 8.972 & $\mathrm{I}$ & .003 \\
\hline N of Valid Cases & 384 & & \\
\hline
\end{tabular}

Table I3. Digital Content \& Services and Chi-Square Test

\begin{tabular}{llll}
\hline Chi-Square Tests & & & \\
\hline & Value & Df & Asymp. Sig. (2-sided) \\
\hline Pearson Chi-Square & $\mathbf{3 5 . 7 9 2}^{\mathrm{a}}$ & $\mathrm{I} 6$ & .003 \\
\hline Likelihood Ratio & 34.685 & $\mathrm{I} 6$ & .004 \\
\hline Linear-by-Linear Association & 8.972 & $\mathrm{I}$ & .003 \\
\hline N of Valid Cases & 384 & & \\
\hline
\end{tabular}

Table I4. E-government, Digital Economy, and Kendall's tau b Test

\begin{tabular}{lllrr}
\hline & & Health Value & Attitude \\
\hline Kendall's tau_b & E-government & Correlation Coefficient & 1.000 & $.292 * *$ \\
\hline & & Sig. (2-tailed) & 384 & .000 \\
\hline & $\mathrm{N}$ & $.292 * *$ & 393 \\
\hline & Correlation Coefficient & .000 & 1.000 \\
\hline & Sigital Economy & Sig. (2-tailed) & 384 & 393 \\
\hline
\end{tabular}


Table 15. Digital Infrastructure, Digital Economy, and Kendall's tau b Test

\begin{tabular}{lllrr}
\hline & & \multicolumn{2}{c}{ DS Purchase Intention } \\
\hline Kendall's tau_b & Digital infrastructure & Correlation Coefficient & 1.000 & $.295^{* *}$ \\
\hline & & Sig. (2-tailed) &. & .000 \\
\hline & & $\mathrm{N}$ & 384 & 384 \\
\hline & Digital & Correlation Coefficient & $.295^{* *}$ & .000 \\
\cline { 2 - 5 } & Economy & Sig. (2-tailed) & 384 & 384 \\
\hline
\end{tabular}

*. Correlation is significant at the 0.0I level (2-tailed).

Table I6. Digital Readiness, Digital Economy and Kendall's tau b Test Correlations

\begin{tabular}{|c|c|c|c|c|}
\hline & & & Health Knowledge & Attitude \\
\hline \multirow[t]{6}{*}{ Kendall's tau_b } & Digital readiness & Correlation Coefficient & 1.000 & $.262 * *$ \\
\hline & & Sig. (2-tailed) & & .000 \\
\hline & & $\mathrm{N}$ & 384 & 384 \\
\hline & Digital Economy & Correlation Coefficient & $.262 * *$ & 1.000 \\
\hline & & Sig. (2-tailed) & .000 & \\
\hline & & $\mathrm{N}$ & 384 & 384 \\
\hline
\end{tabular}

* Correlation is significant at the 0.0I level (2-tailed).

Table 17. Digital Content \& Services, Digital Economy, and Kendall's tau b Test

\begin{tabular}{|c|c|c|c|c|c|}
\hline & & & Health Knowledge & $\begin{array}{l}\text { DS Purchase } \\
\text { Intention }\end{array}$ & \\
\hline \multirow[t]{8}{*}{ Kendall's tau_b } & Digital content & Correlation & 1.000 & & $.251 * *$ \\
\hline & \& Services & Coefficient & & & \\
\hline & & Sig. (2-tailed) & & & .000 \\
\hline & & $\mathrm{N}$ & 384 & & 384 \\
\hline & Digital & Correlation & $.251^{* *}$ & & 1.000 \\
\hline & Economy & Coefficient & & & \\
\hline & & Sig. (2-tailed) & .000 & & \\
\hline & & $\mathrm{N}$ & 384 & & 384 \\
\hline
\end{tabular}

\section{Summary of Analysis}

Table 18. Hypotheses Testing Summary

\begin{tabular}{lll}
\hline Item & Hypothesis Statement test & Result \\
\hline HI & E-government is positively related to the influence of the digital economy & Accepted \\
\hline H2 & Digital infrastructure is positively related to the influence of the digital economy & Accepted \\
\hline H3 & Digital readiness is positively related to the influence of the digital economy & Accepted \\
\hline H4 & Digital content and services are positively related to the influence of the digital economy & Accepted \\
\hline
\end{tabular}

7. Conclusion

This chapter affords the dialogue and ends approximately the find it examiner, challenge and as well as futurity experiment 


\section{I Study on Findings}

At fast, it is far thrilling that the study from this seems at observed the people have no dating on the E-government, virtual infrastructure, virtual readiness, digital content material, and offerings with the virtual economy. Therefore, this result is not regular with the preceding findings acquired with the aid of Kennedy et al. (2013) and Ong et al. (2014) discovered out that digital economic system is most commonplace amongst ladies regarding E-authorities, virtual infrastructure, virtual readiness, digital content material and services girls. In other words, it means that can't be judged through gender. it could be quality explained that virtual economy is not best not unusual amongst ladies in Malaysia, however, it is also not unusual amongst guys in recent times as Malaysians have become extra digital financial system conscious (The celebrity online, 2017a). Similarly, it additionally may be defined that clients in Malaysia likely are more pick on the virtual economic system.

Alternatively, this observes additionally exhibits that the training stage also has no relationship to digital infrastructure and the virtual economy. Accordingly, this results additionally inconsistent with the result acquired by way of Bailey et al. (2010), Paul and Rana (2012), and Dickinson \& Mackay (2014), which of their studies found that better education level becomes connected with the virtual economic system. Its way that, for the populace in Malaysia, E-government and digital financial system relationships cannot be chosen via their schooling level. It could exceptionally explain that people with better education levels might decide on E-authorities and digital economic system wonderful relationship (Huffington put up, 20II). Similarly, the virtual infrastructure is typically less expensive as compared to physical infrastructure. On the other hand, human beings with low schooling stage might affect on using of E-government with the digital economic system.

From the study provided a solution to the $I^{\text {st }}$ research finding or not E-government and Digital systems are motivated via demographic data. And 2nd research findings on this examination observed that purchasers' features have a sizeable connection with E-government \& virtual financial system. It way that the information stage will affect the E-authorities, and the virtual economy relationship. Moreover, the findings display that there is a vast nice relationship between E-authorities with the virtual economic systems. This result is constant with the findings from Conner et al. (200I), Tromp et al. (2005), Jun et al. (2014), and Dickinson \& Mackay, (20I4). In different phrases, people with higher E-government centers are much more likely to have a high-quality impact on the virtual economy. On top of that digital content and offerings also indicates a widespread fantastic relationship with the digital financial system. This locating is helping by using de Magistris \& Gracia (2013) also using Harris and Thomas (2016) and Hsu et al. (2016). Digital readiness can influence the digital economic system. Consequently, the Ministry of ICT should have post greater effort on teaching human beings in the course of Malaysia approximately E-authorities related difficulty in Malaysia. The feature will affect digital readiness and the digital economy. Thirdly, this study observed out that have an impact on and manage together with digital readiness, and virtual economic system has proven a wonderful importance courting. It implies that better virtual readiness will extra tend to persuade the virtual financial system. The findings are constant with preceding research Conner et al (200I), Conner et al (2003), Chen (2007), Chung et al. (20I2), Emanual et al. (2013). With the development of generation, human beings can now be without problems prompted by way of digital readiness and virtual economy. Next, it's far observed out that there's a nice widespread courting between E-authorities with the virtual economy. This result is regular with the findings that acquired from Chen, (2007) and Gabriels \& Lambert, (2013), which inform that there may be high quality have an effect on E-government on the virtual economic system. However, this relationship could be very sturdy amongst the populace in urban areas of Malaysia. E-government for the city population is plenty greater encouraged by using the digital economy system. furthermore, it is found out that there may be a high-quality extensive courting among digital infrastructure and virtual economic systems; high-quality enormous courting with the digital content material and services with digital economy. The finding is steady with the result received via Chung et al. (2012) which discovered that virtual readiness changed into a robust impact inside the formation of a digital economic system. Further, the finding additionally consistent with the previous studies acquired by using Okleshen Peters et al. (2004) and Chen (2007) that higher virtual content material and services will have an impact on the virtual economic system. Those factors controlled to respond to the third research query on whether or not virtual content material and offerings will affect the digital financial system. In the end, the result of this study discovered that there is a significant relationship among the digital content material and offerings and digital financial system. The virtual content material and offerings determined out to be the most powerful predictor of the virtual economic system on this observe. The finding is constant with the result acquired from Armitage and Conner (200I). this is regular with the locating acquired with the aid of Chung et al. (2012). The end of the result of these paper virtual content and services and virtual economy courting.

\subsection{Implications}

Even though I/2 of the population in Malaysia avail E-authorities and digital economy centers but growing at an alarming level. I.8 million of the 3.5 million human beings in Malaysia have been no longer alert they had been lacked in the back of E-governance and the digital financial system in Malaysia has improved to $17.5 \%$ in 2015 from $15.2 \%$ in 201 I (New Straits instances, 2016). Hence, there are many things that need to be done to raise focus in Malaysia to create an E-government dominated society for the present day and new era. in line with the demography attribute seen on table 4.2 from the preceding section where male come up with $52.8 \%$ of a general interview at the same time as a lady at $48.2 \%$. From the interview total respondents' people where most 
of the people respondents under 40 years' antique, that is generation $\mathrm{Y}$ and $\mathrm{Z}$. also we got most of the respondents to possess a bachelor's degree, followed through a secondary level and diploma as their highest schooling stage. as a result, the subsequent Those involved are being offered to deal with this class of people

First, each individual always wants to stay updated with the digital economy. no one desires to the back of the Egovernment have to prepare digital economy thought to communicate to their human beings at the time whilst selling digital economy. Each gender business must be targeted similarly as E-government associated difficulty in recent times appears uniformly concerned via male and lady.

Secondly, for Gen Y and Z, the digital financial system is indicated through both correct. Government knowledge is critical for them in preserving the proper virtual economic system. a hectic life-style had changed our economic lifestyles. A have a look at also reveals that lengthy-term hit E-authorities can build a sturdy digital economy (The celebrity on line, 2017). thus, man or woman ought to encourage E-authorities for establishing a digital economic system. As such, digital economy know-how should be included in our schooling machine as a middle problem. The government should beautify our training gadget by using integrating the crucial of the digital financial system into the syllabus of number one and secondary school.

Thirdly, an era is primary to Gen Y and Gen Z digital financial system practices. A remark from pals and own family contributors can significantly affect the digital economic system of Gen Y and Z. E-government becomes so powerful with the help of technology along with the net and social media including Facebook. Also, digital word-of-Mouth (E-WOM) has also come to be a powerful and important tool on social media, which can be adopted by E-government to grow their attention to the virtual economic system. Thru social media, humans can share their notion, opinion, and remark about the virtual financial system with their pals and own family participants on social media. As a result, this E-government sure will influence peoples' attitudes towards the digital financial system. one of the success stories that undertake E-government as their device is EDEKA, considered one of the most important economies in Germany, had efficaciously hooked up a connection with its human beings and will increase their consciousness about digital economic system via social media (Business Wired, 2015).

Fourthly, fact search is a crucial level inside the virtual financial system. The millennial technology had extensively used the net to collect statistics. A generation had made records will become very reasonably-priced and may be acquired in a completely fast manner whenever and anyplace. compared to standard media together with television, radio, mag, and newspaper, net technology can now without difficulty search and obtain information from the net. E-government ought to sell its virtual economy through the social media platforms. Cyberspace permits the virtual economic system to attain its goal population in a rapid and fee efficient manner. similarly, educated humans could be capable of interpreting records easily.

Final however not least, Gen $\mathrm{Y}$ and $\mathrm{Z}$ will always like to examine an E-government with the virtual economy. with the intention to grow the virtual economic system of a populace, we need to positioned greater effort on E-government. To lower down the charge, the authorities have to additionally encourage the digital economic system in Malaysia through some incentive applications. further, the E-authorities can also beautify our e-tax device by means of introducing tax comfort for the virtual economy. By using doing this, it may encourage Malaysian to people toward the digital financial system

\subsection{Limitations and Future Studies}

This has a look at has three boundaries as following:

First, the questionnaire used in this study comprises a few technical periods that appear to be hard for apprehend via respondents. In destiny, the questionnaire has to layout in any such manner by way of formed of different languages including Malay and Mandarin to help the respondent to apprehend that means of the questions and thus Improve statistical correctness was collection.

Secondly, this study is restrained to the most effective one important city in Kuala Lumpur. Consequently, A summary of the results may not be complete. Hence, inside in the future, the have a look at other must be included fundamental urban area and metropolitan area consisting of Miri, Bintulu and, Kuching even to other cities in Malaysia.

Ultimately, this has a look at best consists of gender and schooling level because there is demographic variable. therefore, inside the destiny, different a demographic variable together with age and income stage ought must be included on this research result an extended offer knowledge of Impressive thing E-authorities and virtual economy courting

\subsection{Conclusion}

This vision has achieved a specific objective by determining the factors that influence electronic power and the digital economy. This takes a look at found out that mindset is the strongest component that has a wonderful courting to have an impact on the digital financial system. Then again, A virtual financial system can be inspired by different variables. Digital infrastructure located out to have a high-quality relationship with the digital economy, equal as fantastic courting of digital readiness with the virtual financial system. Digital content and services show a strong relationship with the virtual economic system. Further, it's far located that demographic variables including gender and education stage have no widespread relationship with E-government and digital economic system. 


\section{References}

Ajzen, I. (200I). Nature and operation of attitudes. Journal of the annual reviews, 52, $27-58$. http://dx.doi.org/I0.I I46/annurev.psych.52.I.27

Bélanger, F. \& Carter, L. (2012). Digitizing government interactions with constituents: a historical review of e-government research in information systems. Journal of the Association for Information Systems, 13(5), 363394.http://dx.doi.org/I0.I7705/Ijais.00295

Bertot, J.C., Jaeger, P. T. \& Grimes, J. M. (20I0). Using ICTs to create a culture of transparency: e-government and social media as openness and anti-corruption tools for societies, Government Information Quarterly. Journal of Social Sciences and Humanities , 27(3), 264-27I. http://dx.doi.org/I0.I269I/wjssh-3-2-I

Björn, N., Elena, G. \& Ralf, P. (2012). The digital divide vs. the e-government divide: do social-demographic variables (still) impact e-government use among onliners?. Proceedings of European Conference on Information Systems, 2012, I0-I3 June, Barcelona, 199, November 5, 2017. Retrieved from http://aisel.aisnet.org/ecis2012/I99

Bretschneider, S. (2003). Information technology, e-government, and institutional changel. Public Administration Review, Published by Wiley on behalf of the American Society for Public Administration, 63(6), 738-74I. Retrieved from https://www.jstor.org/stable/i28290I

Brynjolfsson, E. \& McAfee, A. (20II). Race against the machine: How the digital revolution is accelerating innovation. driving productivity, and irreversibly transforming employment and the economy, MIT Center for Digital Business, Cambridge. Retrieved from http://ebusiness.mit.edu/research/Briefs/Brynjolfsson_McAfee_Race_Against_the_Machine.pdf

BusinessWired. (20I5). Retrieved April 2018, from https://businesswired.wordpress.com/2015/09/22/case-study-word-ofmouth-in-the- social-media-age-edeka/

Carlsson, B. (2004). The digital economy: what is new and what is not?. Structural Change and Economic Dynamics, I5(3), 245264. http://dx.doi.org/I0.IOI6/j.strueco.2004.02.00I

Chang, I.C., Li, Y.-C., Hung, W.-F., \& Hwang, H.-G. (2005). An empirical study on the impact of quality antecedents on taxpayers, acceptance of internet tax-filing systems. Government Information Quarterly, 22(3), 389-4I0. Retrieved from https://issuu.com/academic-conferences.org/docs/ejise-volumeI9-issue3-articleI024

Chinn, M.D. \& Fairlie, R.W. (2006). ICT use in the developing world: an analysis of differences in computer and Internet penetration. IZA Discussion, 2206, Bonn. Available at SSRN https://ssrn.com/abstract=920648

Central Intelligence Agency (CIA). (20II). The World Facebook, October 9, 2017 Retrieved from www.cia.gov/library/publications/download/download-20I I/

Cooper, R.B. \& Zmud, R.W. (1990). Information technology implementation research: a technological diffusion approach. Management science, 36(2), I23-I39. http://dx.doi.org/I0.1287/mnsc.36.2.123

Cordella, A. \& Iannacci, F. (2010). Information systems in the public sector: the e-government enactment framework. The Journal of Strategic Information Systems, I9(I), 52-66. http:/ / dx.doi.org/I0.5555/I75226I.I7525I6

Coursey, D. \& Norris, D.F. (2008). Models of e-government: are they correct? An empirical assessment. Public Administration Review, 68(3), 523-536. http://dx.doi.org/I0.1086/228943

Carlson, J. P., Vincent, L. H., Hardesty, D. M., \& Bearden, W. O. (2009). Objective and subjective knowledge relationships: A quantitative analysis of consumer research findings. Journal of Consumer Research, 35(5), 864-876. http://dx.doi.org/I0.I086/593688

Doong, H., Wang, H. \& Foxallc, G.R. (2010). Psychological traits and loyalty intentions towards e-government services. International Journal of Information $\quad$ Management, $\quad 30(5), 457-464$. http://dx.doi.org/I0.IOI6/j.ijinfomgt.2010.01.007

Davis, F.D. (1989). Perceived usefulness, perceived ease of use and user acceptance of information technology. MIS Quarterly, I3(3), 3I9-340. http://dx.doi.org/I0.2307/249008

Davis, F.D., Bagozzi, R.P. \& Warshaw, P.R. (I992). Extrinsic and intrinsic motivation to use computers in the workplace. Journal of Applied Social Psychology, 22(I4), I I I I-I I32. http://dx.doi.org/I0.I I I / j.I559-I8I6.I992.tb00945.x

Dunleavy, P. \& Margetts, H. (2010). The second wave of digital era governance. American Political Science Association Conference, Washington, DC, 4 September, available at http://eprints.lse.ac.uk/27684/ (accessed 20 March 2013).

Dunleavy, P., Margetts, H., Bastow, S. \& Tinkler, J. (2006). New public management is dead-Long live digital-era governance. Journal of Public Administration Research and Theory, I6(3), 467-494. http://dx.doi.org/I0.I093/jopart/mui057

Dunleavy, P., Margetts, H., Bastow, S. and Tinkler, J. (2006). Digital era governance: IT corporations, the state, and egovernment. Social Science Computer Review, 26(2). http://dx.doi.org/I0.I I77/08944393073045I5

Economist Intelligence Unit (EIU) (20I0). Digital economy rankings 20I0, Retrieved from https://graphics.eiu.com/upload/EIU_Digital_economy_rankings_20IO_FINAL_WEB.pdf

Erumban, A.A. \& de Jong, S.B. (2006). Cross-country differences in ICT adoption: a consequence of culture? Journal of World Business, 4I(4), 302-3I4. https://doi.org/I0.I0I6/j.jwb.2006.08.005 
Euromonitor. (2016a). Retrieved October 27, 2017, from http://www.euromonitor.com/consumer-health-in-malaysia/report Euromonitor. (2016b). Retrieved October 27, 2017, from http://www.euromonitor.com/vitamins-and-dietary-supplementsin-malaysia/report

Fountain, J.E. (200I). Building the virtual state: Information Technology and Institutional Change, Brookings Inst. Press, Washington, DC. https://doi.org/I0.7864/j.ctvcb59n3

Krishnan, S. Teo, T.S. \& Lim, V.K. (2013). Examining the Relationships among e-government maturity, corruption, economic prosperity, and environmental degradation: a cross-country analysis. Information and Management, 50(8), 638. https://doi.org/I0.1016/j.im.2013.07.003

Kaiser, H. F. (I974). An index of factorial simplicity. Psychometrika, 39, 3I-36. https://doi.org/I0.I007/BF0229I575

Kanyongo, G. Y. (2006). The Influence of Reliability on Four Rules for Determining the Number of Components to Retain. Journal of Modern Applied Statistical Methods, 5(2), 332-343. https://doi.org/I0.22237/jmasm/I I62353960

Marketing Magazine. (2009). Retrieved October 2I, 2017, from http://www.marketingmagazine.com.my/homepage/nielsenone-in-two-malaysians- take-vitamins-and-dietary-supplements

NES. (2015). National Economic Survey (NES). Ministry of Finance, Malaysia. Retrieved from https://www.unescap.org/sites/default/files/04_\%5BAb\%20Wahab\%5D\%20Malaysia\%20ADBI.pdf

NHMS. (2016). National Economic Survey (NHMS). Ministry of Finance, Malaysia. Retrieved from https://www.moh.gov.my/moh/resources/nhmsreport2015vol2.pdf

New Straits Times. (2016). Retrieved May 2018, from http://www.nst.com.my/news/2016/05/I44687/diagnosing-diabetes OECD, Retrieved November 26, 2017. from http://www.oecd.org/internet/broadband/ocedbroadbandportal.htm

Pew Research Centre (2015). Retrieved November 12, 2017. from www.pewresearch.org,

Rokeach, M. (1973). The nature of human values (Vol.438). New York: Free press. https://doi.org/I0.1093/sf/53.4.659

Salkind, N. (2009). Exploring research, 7th Edition. Upper Saddle River, New Jersey: Pearson. Sarawak Government. (2016). Retrieved December 08, 2017, from http://www.sarawak.gov.my/web/home/article_view/240/I75/

Silbiger, S. (2012). The Ten-Day MBA, 4th Edition. New York: HarperCollins.

Spronk, I., Kullen, C., Burdon, C., \& O'Connor, H. (20I4). Relationship between E-governance and the digital economy. British $\begin{array}{llll}\text { Journal of Digital } & \text { Economy, } & \text { IIII(I0), } & \text { I726. }\end{array}$ https: / / ro.uow.edu.au/cgi/viewcontent.cgi?article $=32532$ context $=$ smhpapers

SPU. (2015). Retrieved 03 I2, 2017, from State Planning Unit: Retrieved from http://www.spu.sarawak.gov.my/download/Sarawak\%20Facts\%20\&\%20Figures\%202 0I5.pdf

The Star Online. (201I). The old bones of mine. Retrieved October 20, 20I7, from http://www.thestar.com.my/lifestyle/health/20I I/07/I0/these-old-bones-of-mine/

The Star Online. (2012). Become a statistic. Retrieved November 09, 2017 from http://www.thestar.com.my/lifestyle/health/2012/03/I8/dont-become-a-statistic/

The Star Online. (2014). Digital economy malaysia is fattest country in asia Retrieved October28, 20I7, from http://www.thestar.com.my/news/nation/20I4/0I/I6/digital-economy - malaysia-is-fattest-country-in-se-asia/

The Star Online. (2017a). popular digital expo even. Retrieved May from http://www.thestar.com.my/news/nation/2017/03/II/popular-digital-expo-back-in- april-more-activities-to-beheld-at-this-years-event

Tudoran, A., Olsen, S.O. \& Dopico, D.C. (2009). The effect of E-governance on consumers Digital Economy. Appetite . 52, 568-579. http://dx.doi.org/I0.I080/0I900692.20I0.5I7724

Tapscott, D, \& Agne, D. (I999). Governance in the Digital Economy. Finance and Development, 36(4). $34-37$. Retrieved from https://www.imf.org/external/pubs/ft/fandd/I999/I2/pdf/tapscott.pdf

United Nations (2012), United Nations E-Government Survey 2012: E-Government for the people, United Nations, New York, NY.

World Bank (2008). Definition of e-government. Retrieved $04 \quad$ I5, 2018 from http://web.worldbank.org/website/external/technologies/0.

Yap, S. F., Noor, N. A. M., Marshall, R., \& Liew, K. H. (20I4). Promoting Digital Content and services among young Malaysian: toward an integrated digital economic framework. Australasian Digital Marketing Journal (ADMJ). 22(3), $268-278$. http://dx.doi.org/I0.I I09/NatPC.20I I.6I36267

\section{Copyrights}

Copyright for this article is retained by the author(s), with first publication rights granted to the journal.

This is an open-access article distributed under the terms and conditions of the Creative Commons Attribution license

(http://creativecommons.org/licenses/by/4.0/) 